\title{
Cadmium-induced autophagy is mediated by oxidative signaling in PC-12 cells and is associated with cytoprotection
}

\author{
QI-WEN WANG ${ }^{1-4^{*}}$, YI WANG $^{1,2 *}$, TAO WANG $^{1,2}$, KANG-BAO ZHANG $^{1,2}$, YAN YUAN $^{1,2}$, JIAN-CHUN BIAN $^{1,2}$, \\ XUE-ZHONG LIU ${ }^{1,2}$, JIAN-HONG GU ${ }^{1,2}$, JIA-QIAO ZHU ${ }^{1,2}$ and ZONG-PING LIU ${ }^{1,2}$ \\ ${ }^{1}$ College of Veterinary Medicine, Yangzhou University; ${ }^{2}$ Jiangsu Co-Innovation Center for Prevention and Control of \\ Important Animal Infectious Diseases and Zoonoses, Yangzhou, Jiangsu 225009; ${ }^{3}$ Bijie Pilot Area Research Institute, \\ Guizhou University of Engineering Science, Bijie, Guizhou 551700; ${ }^{4}$ State Key Laboratory Cultivation Base \\ for Cell Differentiation Regulation, Henan Normal University, Xinxiang, Henan 453007, P.R. China
}

Received July 13, 2014; Accepted May 8, 2015

DOI: $10.3892 / \mathrm{mmr} .2015 .3907$

\begin{abstract}
Oxidative stress induced by cadmium (Cd) is a common phenomenon that has been observed in numerous studies. However, the underlying mechanism remains unknown. Recently, exposure of PC-12 cells to Cd has been shown to activate autophagy, which acts as a temporary survival pathway under stressful conditions by delaying the occurrence of apoptosis. The present study investigated the impact of oxidative stress on Cd-induced autophagy in PC-12 cells. The results demonstrated that $\mathrm{Cd}$-induced autophagy (following treatment with $\mathrm{Cd}$ for $4 \mathrm{~h}$ ), increased the levels of intracellular reactive oxygen species (ROS), decreased the mitochondrial membrane potential and resulted in apoptosis. A treatment with chloroquine (CQ; an autophagic inhibitor) sensitized the PC-12 cells to $\mathrm{Cd}$, due to the increased production of ROS, which was associated with the incapacity to reduce mitochondrial and cell death. $\mathrm{N}$-acetyl-L-cysteine, an antioxidant agent, decreased Cd-induced autophagy and reduced intracellular ROS levels, but enhanced CQ-induced apoptotic cell death. These findings indicate that moderate levels of ROS are essential in the regulation of Cd-induced autophagy, which subsequently enhances cell survival. Thus, the results of the present study provide an insight for future investigation of Cd-induced neurotoxicity.
\end{abstract}

Correspondence to: Dr Zong-Ping Liu or Dr Jia-Qiao Zhu, College of Veterinary Medicine, Yangzhou University, 88 South University Avenue, Yangzhou, Jiangsu 225009, P.R. China

E-mail: liuzongping@yzu.edu.cn

E-mail: jqzhu1998@163.com

*Contributed equally

Key words: cadmium, autophagy, reactive oxygen species, chloroquine, PC-12 cells

\section{Introduction}

Cadmium (Cd) is an occupationally and environmentally important toxic metal with no known biological function (1). It is well known that $\mathrm{Cd}$ affects neurological and behavioral impairment, including memory deficits (2), alteration of social contact (3), olfactory dysfunction (4), synaptic function and neurotransmission $(5,6)$. Therefore, $\mathrm{Cd}$ is considered to be a possible etiological factor in neurodegenerative diseases. However, the exact mechanism by which $\mathrm{Cd}$ elicits its neurotoxic effects is not well elucidated.

Impaired mitochondrial function, oxidative stress, accumulation of protein aggregates and autophagic stress are common in many pathologies, including neurodegenerative diseases (7). Oxidative stress is a disturbance of the cellular redox balance in favor of the pro-oxidants, and leads to disruption of cellular macromolecules (for example, degradation of proteins, cross-links in DNA and membrane fatty acid peroxidation). However, elevated reactive oxygen species (ROS) concentrations also influence signal transduction. At the cellular level, $\mathrm{Cd}$ induces oxidative stress in numerous organisms, which results in physiological damage to different organs $(8,9)$. Neurons in the brain are vulnerable to oxidative damage due to their high metabolic activity, low antioxidant capacity and non-replicative nature (10). Excessive quantities of Cd-induced ROS can modify proteins, lipids and DNA, and alter their functions, which contributes to the activation of mTOR signaling and leads to neuronal apoptosis (11). These findings indicate that ROS are important regulators in Cd neurotoxicity.

Autophagy is a catabolic process that responds to starvation or other stress conditions whereby cell constituents (damaged organelles, unfolded proteins and intracellular pathogens) are engulfed within autophagosomes and eventually degraded by lysosomal enzymes to sustain cellular homeostasis $(12,13)$. However, a massive and persistent autophagy may result in cell death, termed autophagic cell death (14). Autophagy is largely considered to be non-selective, where preferential autophagy of damaged or excess organelles (including the endoplasmic reticulum and mitochondria) occurs. However, there is accumulating evidence for selective autophagic processes in response to ROS $(10,15)$. Our previous study demonstrated that 
exposure of PC-12 cells to Cd stimulates autophagy, which serves as a temporary survival pathway in cells under stress by delaying the occurrence of apoptosis (16). The aim of the present study was to determine the association between oxidative stress and Cd-induced autophagy in PC-12 cells.

\section{Materials and methods}

Materials. RPMI-1640 medium, fetal bovine serum (FBS) and horse serum were purchased from Life Technologies (Grand Island, NY, USA). $\mathrm{Cd}\left(\mathrm{CH}_{3} \mathrm{COO}\right)_{2} \cdot 3 \mathrm{H}_{2} \mathrm{O}(\mathrm{Cd}), \mathrm{N}$-acetyl-Lcysteine (NAC), 2-,7-dichlorofluorescein diacetate (DCFH-DA), polyclonal rabbit anti-LC3B (cat. no. L7543), monodansylcadaverine (MDC), chloroquine (CQ) and poly-L-lysine were purchased from Sigma-Aldrich (St. Louis, MO, USA). JC-1, a bicinchoninic acid (BCA) protein assay kit was provided by Beyotime Institute of Biotechnology (Haimen, Jiangsu, China) and propidium iodide (PI) was purchased from BD Pharmingen (San Diego, CA, USA). Monoclonal rabbit anti- $\beta$-actin (cat. no. 4970), horseradish peroxidase (HRP)- and fluorescein isothiocyanate (FITC)-conjugated goat anti-rabbit IgG (cat. nos. 7074 and 4412, respectively) were obtained from Cell Signaling Technology, Inc. (Danvers, MA, USA). The enhanced chemiluminescence (ECL) solution (SuperSignal Chemiluminescent HRP substrate) was obtained from Thermo Fisher Scientific, Inc. (Waltham, MA, USA) and lactate dehydrogenase (LDH) was purchased from Beckman Coulter, Inc. (Brea, CA, USA).

Cell cultures. The rat pheochromocytoma cell line, PC-12 was purchased from the Type Culture Collection of the Chinese Academy of Sciences (Shanghai, China). The PC-12 cell line was cultured in an antibiotic-free RPMI-1640 medium (temperature, $37^{\circ} \mathrm{C}$; atmosphere, $5 \% \mathrm{CO}_{2}$ ), which was supplemented with $10 \%$ heat-inactivated horse serum and 5\% FBS.

Immunofluorescence. The PC-12 cells $\left(2.0 \times 10^{5}\right.$ cells $\left./ \mathrm{ml}\right)$ were cultivated on cover slips that were pre-coated with poly-L-lysine and treated with $20 \mu \mathrm{mol} / 1 \mathrm{Cd}$ for $4 \mathrm{~h}$. After washing in phosphate-buffered saline (PBS), the cells were fixed with $4 \%$ paraformaldehyde in PBS for 30 min at $4^{\circ} \mathrm{C}$, permeabilized with $0.5 \%$ Triton X-100 (Nanjing Jiancheng Bioengineering Institute, Nanjing, China) and blocked with $5 \%$ bovine serum albumin (Beijing Solarbio Science \& Technology Co., Ltd., Beijing, China) for $20 \mathrm{~min}$ at room temperature. The cells were incubated with anti-LC3B rabbit antibody in a blocking solution for $2 \mathrm{~h}$, washed in blocking solution and stained with FITC-conjugated anti-mouse IgG for $1 \mathrm{~h}$. The cell nuclei were subsequently stained with DAPI. Following washing, the samples ( 300 cells) were observed under a fluorescence microscope (Leica DMI3000 B; Leica Microsystmes, Wetzlar, Germany).

Labeling of autolysosome with MDC. PC-12 cells $\left(2.5 \times 10^{5}\right.$ cells $\left./ \mathrm{ml}\right)$ were grown on cover slips, pretreated with or without $5 \mu \mathrm{mol} / 1 \mathrm{CQ}$ for $30 \mathrm{~min}$, followed by treatment with or without $20 \mu \mathrm{mol} / 1 \mathrm{Cd}$ for a further $4 \mathrm{~h}$. After incubation, cells were washed in PBS and fixed for 30 min using a fresh solution of $4 \%$ paraformaldehyde. Following staining with $50 \mu \mathrm{mol} / \mathrm{l} \mathrm{MDC}$, the cells were immediately analyzed by fluorescence microscopy (Leica DMI3000 B).
Transmission electron microscopy. Treated cells were washed and fixed for $30 \mathrm{~min}$ in $2.5 \%$ glutaraldehyde. The samples were treated with $1.5 \%$ osmium tetroxide, dehydrated with alcohol and embedded in epoxy resins. The ultrathin sections were contrasted with uranyl acetate and lead citrate for electron microscopy. Electron micrographs were obtained using a Philips CM120 transmission electron microscope (Philips, Eindhoven, The Netherlands).

Western blot analysis. PC-12 cells $\left(3.0 \times 10^{5}\right)$ were preincubated with $100 \mu \mathrm{mol} / 1 \mathrm{NAC}$ for $1 \mathrm{~h}$, and were then incubated with $20 \mu \mathrm{mol} / \mathrm{l} \mathrm{Cd}$ for a further $4 \mathrm{~h}$. Following treatment, the cells were washed twice with cold PBS, extracted into RIPA lysis buffer on ice for $30 \mathrm{~min}$, sonicated for $10 \mathrm{sec}$ and centrifuged at $12,000 \mathrm{x}$ g for $10 \mathrm{~min}$ at $4^{\circ} \mathrm{C}$. The protein content was determined using a BCA protein assay kit. Equal quantities of protein samples $(60 \mu \mathrm{g})$ were uploaded and separated by $15 \%$ sodium dodecyl sulfate-polyacrylamide gel electrophoresis, and transferred onto nitrocellulose membranes. The membranes were blocked in 5\% nonfat milk in Tris-buffered saline with $0.1 \%$ Tween-20 at room temperature for $2 \mathrm{~h}$, and incubated with the indicated primary antibodies (anti-LC3B, 1:1,000; anti- $\beta$-actin, 1:2,000) overnight at $4^{\circ} \mathrm{C}$ and with HRP-conjugated secondary antibodies at room temperature for $1.5 \mathrm{~h}$. The signal was detected using ECL reagents. The band intensity was determined using the gel image analysis system, Image Lab version 2.0.1 (BioRad Laboratories, Inc., Hercules, CA, USA) and was normalized against $\beta$-actin.

ROS determination. Following treatment, the cells were collected, incubated with $20 \mu \mathrm{mol} / 1 \mathrm{DCFH}-\mathrm{DA}$ at $37^{\circ} \mathrm{C}$ for $20 \mathrm{~min}$ in the dark, and washed twice with PBS. The cells were analyzed using a FACSAria flow cytometer (BD Biosciences, San Jose, CA, USA).

Mitochondrial membrane potential $\left(\Delta \Psi_{m}\right)$ assay. Changes in the $\Delta \Psi \mathrm{m}$ were measured by flow cytometry using JC-1 dye. Following treatment, cells were selected and incubated in a JC-1 staining solution for $20 \mathrm{~min}$ at $37^{\circ} \mathrm{C}$. The cells were subsequently rinsed twice with the JC- 1 staining buffer. The fluorescence intensity of the mitochondrial JC-1 monomers and aggregates was detected using flow cytometry. The $\Delta \Psi \mathrm{m}$ of the PC-12 cells was calculated as the ratio of red (aggregates) to green (monomers) fluorescence.

PI staining to assess DNA fragmentation. The PI staining assay and flow cytometry were used to evaluate the extent of cell death. Apoptotic cells are characterized by a hypoploid DNA fluorescence pattern (17). Briefly, following treatment, cells were collected and suspended in $100 \mu \mathrm{l}$ binding buffer containing $5 \mu \mathrm{l}$ PI dye solution. Following incubation in the dark at $25^{\circ} \mathrm{C}$ for $25 \mathrm{~min}$, the cells were analyzed using a FACSAria flow cytometer.

LDH activity assay. Following treatment, the supernatant of the cell culture was harvested. The PC-12 cells were rinsed with PBS and lysed with $1 \%$ Triton $\mathrm{X}-100$ at $37^{\circ} \mathrm{C}$ for $30 \mathrm{~min}$. The supernatants and cell lysates were prepared according to the manufacturer's instructions for the LDH assay and examined using an automatic biochemical analyzer (AU480; Beckman 
A
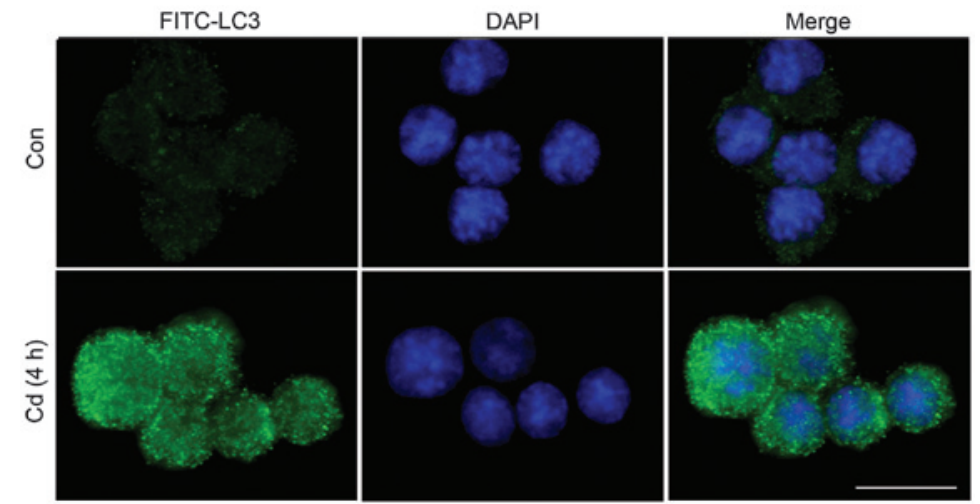

B

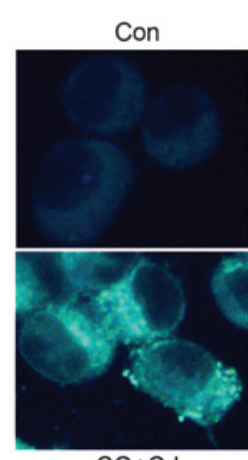

$\mathrm{CQ}+\mathrm{Cd}$

C
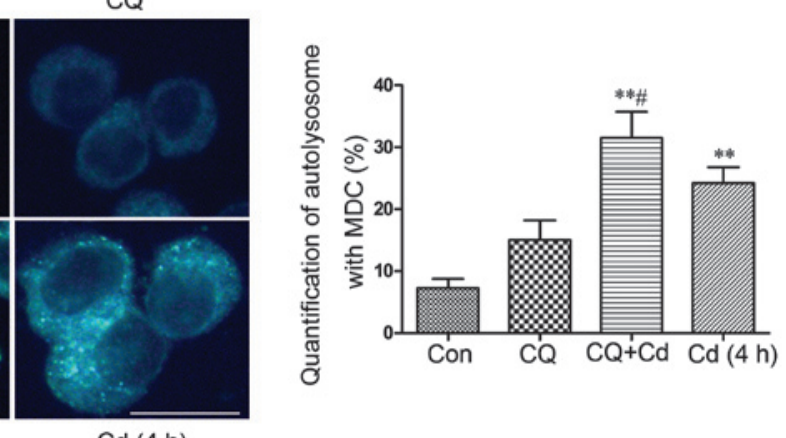

Cd $(4 \mathrm{~h})$

D

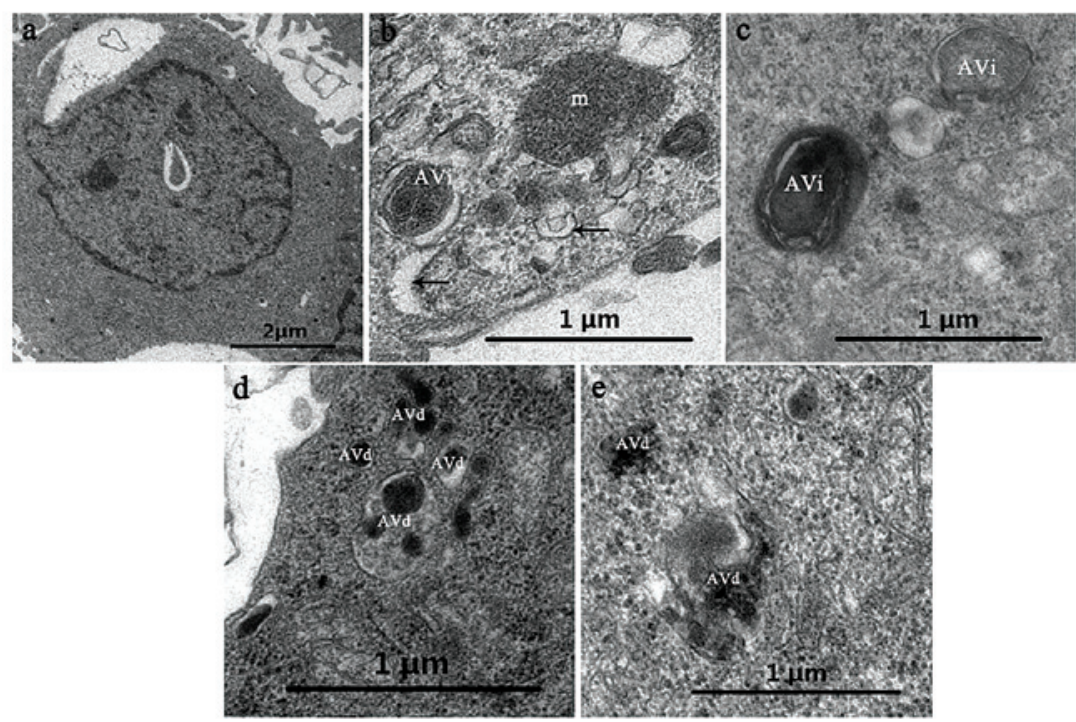

Figure 1. Activation of autophagy. (A) PC-12 cells were treated with $20 \mu \mathrm{mol} / 1 \mathrm{Cd}$ for $4 \mathrm{~h}$ and stained by indirect immunofluorescence. (B) PC-12 cells were pretreated with $5 \mu \mathrm{mol} / 1 \mathrm{CQ}$ for $30 \mathrm{~min}$, followed by treatment with $20 \mu \mathrm{mol} / \mathrm{l} \mathrm{Cd}$ for another $4 \mathrm{~h}$. MDC staining analysis was performed by fluorescence microscopy. (C) Quantitation of $\sim 300$ cells containing autolysosomes, reported as the mean \pm standard deviation; ${ }^{* *} \mathrm{P}<0.01$, compared with the control and ${ }^{\#} \mathrm{P}<0.05$ compared with the $\mathrm{Cd} 4 \mathrm{~h}$ group (bar $=10 \mu \mathrm{m}$ ). (D) Transmission electron microscopy analysis. (a) Untreated control cells demonstrating normal distribution of organelles; (b-e) autophagic compartments at various stages. Cup-shaped membranous structures in the cytoplasm are indicated by the arrows. $\mathrm{m}$, mitochondria; AVi, initial autophagosome; AVd, degradative autophagosome. FITC-LC3, fluorescein isothiocyanate-light chain 3; Con, control; Cd, cadmium; $\mathrm{CQ}$, chloroquine; MDC monodansylcadaverine.

Coulter, Inc.). The LDH result is expressed as the proportion of leakage with respect to the total level of LDH.

Statistical analysis. Results are presented as the mean \pm standard deviation (SD). Significance was assessed by one-way analysis of variance following appropriate transformation to normalized data and equalized variance where required. Statistical analysis was performed using IBM SPSS statistics 19.0 (IBM SPSS,
Armonk, NY, USA) and $\mathrm{P}<0.05$ was considered to indicate a statistically significant difference.

\section{Results}

Activation of autophagy. The distribution of endogenous LC3-II in cells prior to and following Cd treatment for $4 \mathrm{~h}$ was monitored by indirect immunofluorescence staining to 
A

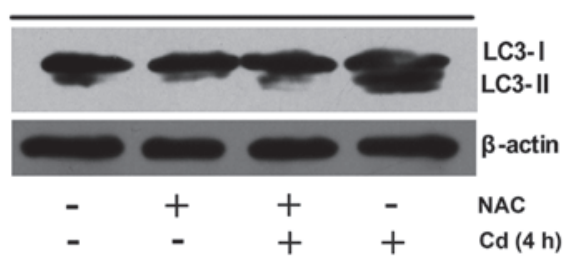

B

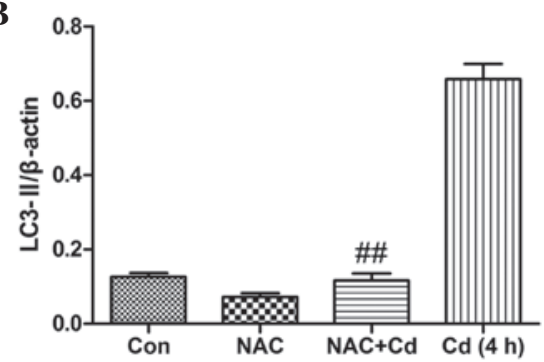

C

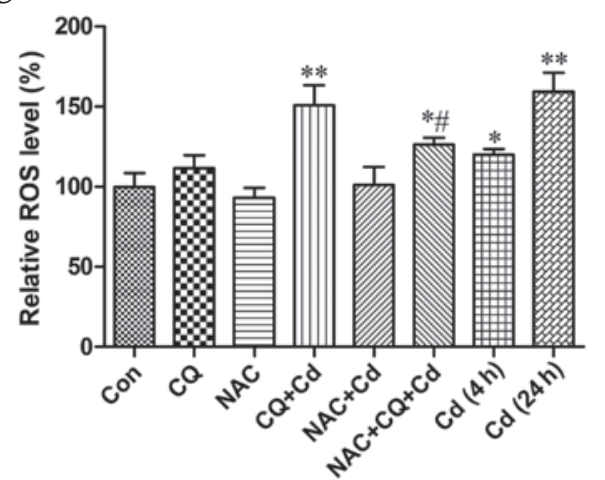

Figure 2. Involvement of ROS in Cd-induced autophagy. PC-12 cells were pretreated with $100 \mu \mathrm{mol} / 1 \mathrm{NAC}$ for $1 \mathrm{~h}$ and subsequently exposed to $20 \mu \mathrm{mol} / 1$ $\mathrm{Cd}$ for $4 \mathrm{~h}$. (A) Western blot analysis was performed and $\beta$-actin served as a loading control. (B) The blot for LC3-II was semi-quantified using Image Lab (Bio-Rad). Results are presented as the mean \pm standard deviation $(\mathrm{n}=3$; bar $=10 \mu \mathrm{m}) .{ }^{\# \#} \mathrm{P}<0.01$ compared with the Cd group. (C) PC- 12 cells were preincubated with $5 \mu \mathrm{mol} / 1 \mathrm{CQ}$ for $30 \mathrm{~min}$ and/or $100 \mu \mathrm{mol} / 1 \mathrm{NAC}$ for $1 \mathrm{~h}$, and incubated with $20 \mu \mathrm{mol} / 1 \mathrm{Cd}$ for another $4 \mathrm{~h}$. Or the PC-12 cells were treated with $20 \mu \mathrm{mol} / 1$ $\mathrm{Cd}$ for $24 \mathrm{~h}$. The ROS levels were examined by flow cytometry $(\mathrm{n}=3)$. ${ }^{*} \mathrm{P}<0.05,{ }^{* *} \mathrm{P}<0.01$ compared with the control, and ${ }^{*} \mathrm{P}<0.05$ compared with the co-treatment group of Cd and CQ. LC3, light chain 3; NAC, N-acetyl-L-cysteine; Cd, cadmium; Con, control; ROS, reactive oxygen species; CQ, chloroquine.
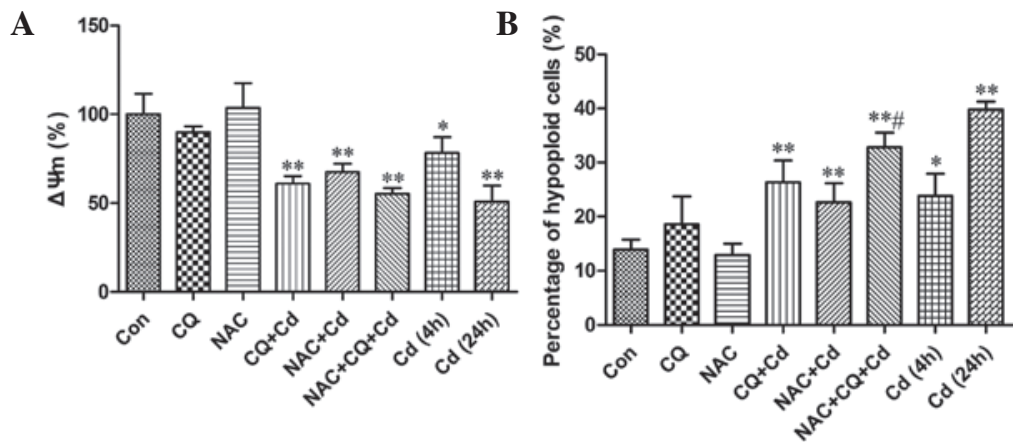

C

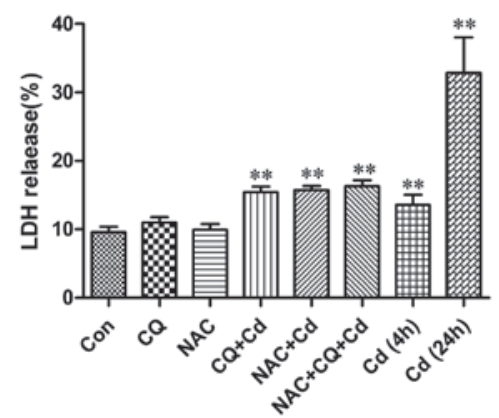

Figure 3. Roles of ROS and autophagy in Cd-induced cytotoxicity. PC-12 cells were preincubated with $5 \mu \mathrm{mol} / 1 \mathrm{CQ}$ for $30 \mathrm{~min}$ and/or $100 \mu \mathrm{mol} / 1 \mathrm{NAC}$ for $1 \mathrm{~h}$, then incubated with $20 \mu \mathrm{mol} / 1 \mathrm{Cd}$ for another $4 \mathrm{~h}$. Or PC-12 cells were treated with $20 \mu \mathrm{mol} / 1 \mathrm{Cd}$ for $24 \mathrm{~h}$. (A) Flow cytometry was used to examine changes in the $\Delta \Psi \mathrm{m}$, (B) hypoploid apoptotic cell numbers were determined by propidium iodide staining and (C) the LDH assay was detected using a cell viability assay kit $(\mathrm{n}=3) .{ }^{*} \mathrm{P}<0.05,{ }^{* *} \mathrm{P}<0.01$ compared with the control, and ${ }^{\#} \mathrm{P}<0.05$ compared with the co-treatment group of $\mathrm{Cd}$ and $\mathrm{CQ} . \Delta \Psi \mathrm{m}, \mathrm{mitochondrial} \mathrm{membrane}$ potential; Con, control; CQ, chloroquine; NAC, N-acetyl-L-cysteine; Cd, cadmium; LDH, lactate dehydrogenase; ROS, reactive oxygen species.

examine whether autophagy was induced by Cd treatment. As demonstrated in Fig. 1A, a greater number of dots were apparent in Cd-treated neurons when compared with the control cells. In addition, the treated cells were stained with 


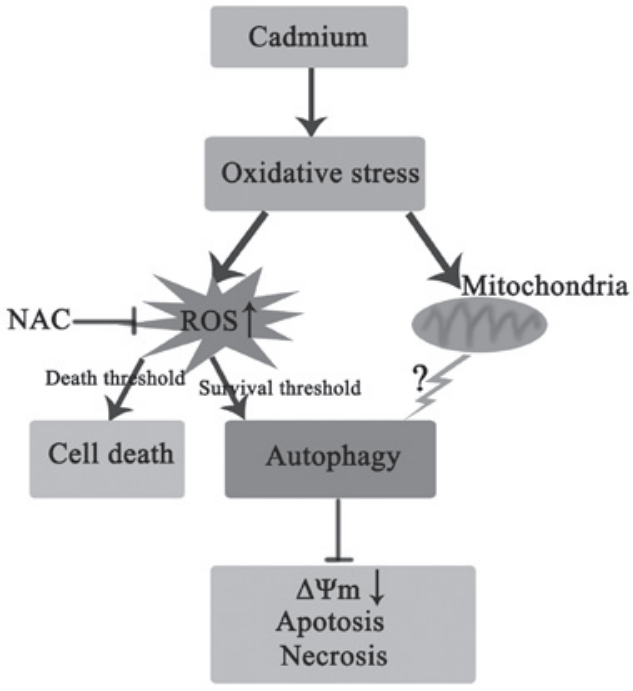

Figure 4. Schematic of the association between autophagy and oxidative stress in Cd-treated PC-12 cells. NAC reduces intracellular levels of ROS decreases Cd-induced autophagy, but enhances Cd-induced apoptosis. ROS are essential in the regulation of Cd-induced autophagy, which subsequently enhances cell survival. However, overwhelming levels of ROS may result in cell death. NAC, N-acetyl-L-cysteine; ROS, reactive oxygen species; $\Delta \Psi \mathrm{m}$, mitochondrial membrane potential.

MDC, a fluorescent dye that selectively recognizes autolysosomes (13). The Cd-treated cells reveal a diffuse punctate pattern, which indicates the activation of autophagy, while the control cells demonstrate faint fluorescence (Fig. 1B and $\mathrm{C} ; \mathrm{P}<0.01)$. Following treatment with $\mathrm{CQ}$, which disrupts the function of lysosomes and inhibits autophagy at a late stage, Cd co-treatment resulted in the accumulation of large MDC-positive vesicles. To further demonstrate that autophagy is induced by $\mathrm{Cd}$, transmission electron microscopy was performed on untreated or Cd-treated cells. As depicted in Fig. 1D, Cd-treated cells exhibited cup-shaped membranous structures, and initial and degradative autophagosome structures that were not present in the control cells. Furthermore, western blot analysis revealed that the levels of LC3-II protein markedly increased following $\mathrm{Cd}$ treatment (Fig. 2A). These results indicate that $\mathrm{Cd}$ treatment induces autophagy in $\mathrm{PC}-12$ cells.

Involvement of ROS in Cd-triggered autophagy. To identify whether the ROS scavenger, NAC exerts an effect on Cd-induced autophagy, western blot analysis was conducted. As Fig. 2A and B demonstrate, compared with the Cd treatment group, the antioxidant, NAC significantly inhibited the LC3-II protein level $(\mathrm{P}<0.01)$. The result indicates that $\mathrm{Cd}$-mediated autophagy may be blocked by NAC and ROS production may be involved in inducing autophagy.

To further identify the above-mentioned hypothesis, ROS levels were assessed using flow cytometry. As shown in Fig. 2C, treatment of PC-12 cells with Cd for $4 \mathrm{~h}$ and $24 \mathrm{~h}$ increased intracellular ROS levels significantly $(\mathrm{P}<0.05$ and $\mathrm{P}<0.01$, respectively) compared with the control. Co-treatment with $20 \mu \mathrm{mol} / \mathrm{l} \mathrm{Cd}$ and CQ for $4 \mathrm{~h}$ also significantly increased ROS production when compared with the control group $(\mathrm{P}<0.01)$. However, NAC reduced the ROS concentrations that were induced by $\mathrm{Cd}$ and $\mathrm{CQ}$ co-treatment $(\mathrm{P}<0.05)$. The result revealed that Cd-mediated autophagy may be dependent on its ability to generate ROS.

Roles of ROS and autophagy in Cd-induced cytotoxicity. In the case of treatment with $20 \mu \mathrm{mol} / \mathrm{l} \mathrm{Cd}$, there was a significant decrease in $\Delta \Psi \mathrm{m}$ following treatment for $4 \mathrm{~h}(\mathrm{P}<0.05)$ and $24 \mathrm{~h}$ $(\mathrm{P}<0.01)$, a 4-h co-treatment of $\mathrm{Cd}$ and $\mathrm{CQ}$ also significantly decreased $\Delta \Psi \mathrm{m}(\mathrm{P}<0.01$; Fig. $3 \mathrm{~A})$. Although the difference was not significant, it appeared that NAC did not prevent, but promoted this event induced by $\mathrm{Cd}$ and CQ treatment in PC-12 cells. The findings indicate that ROS production protects PC-12 cells from inhibiting the decline of $\Delta \Psi \mathrm{m}$ by inducing autophagy.

To examine the role of ROS and autophagy associated with Cd-induced cytotoxicity, a PI staining assay was performed. The results demonstrated that $\mathrm{Cd}$ treatment increased the quantity of hypoploid apoptotic cells following $4 \mathrm{~h}(\mathrm{P}<0.05)$ and $24 \mathrm{~h}(\mathrm{P}<0.01)$ of treatment when compared with the control. Furthermore, CQ augmented the proportion of apoptotic cells following a 4-h treatment with $\mathrm{Cd}(\mathrm{P}<0.01)$. In addition, $\mathrm{PC}-12$ cells that were co-treated with $\mathrm{NAC}, \mathrm{Cd}$ and $\mathrm{CQ}$ further accelerated the apoptosis rate when compared with the CQ and $\mathrm{Cd}$ co-treatment group $(\mathrm{P}<0.05$; Fig. 3B). Collectively, these results indicate that ROS generation inhibits apoptosis by inducing autophagy in PC-12 cells.

For Cd injured PC-12 cells, the LDH leakage rate (Fig. 3C) demonstrated a significant difference when compared with the control group $(9.58 \pm 0.76 \%)$ after cells had been treated with $\mathrm{Cd}$ for $4 \mathrm{~h}(13.56 \pm 1.45 \% ; \mathrm{P}<0.01)$. Furthermore, the LDH leakage rate markedly increased to $32.87 \pm 4.47 \%$ following a $24-\mathrm{h} \mathrm{Cd}$ treatment $(\mathrm{P}<0.01)$. CQ increased the release of $\mathrm{LDH}$ following treatment with $20 \mu \mathrm{mol} / 1 \mathrm{Cd}$ for $4 \mathrm{~h}(15.41 \pm 0.84 \%$; $\mathrm{P}<0.01)$. However, NAC did not protect PC-12 cells against injury that was caused by CQ and Cd co-treatment $(16.05 \pm 0.79 \%)$ (Fig. 3C), indicating that the protective effect of ROS is irrelevant to reducing necrosis.

\section{Discussion}

The bioaccumulation of $\mathrm{Cd}$ has been demonstrated as toxic to humans and environmental health. Cd induces damaging and repair processes in which the cellular redox status is critical (18). Thus, understanding the interface between stress adaptation and cell death/autophagy is important for understanding redox biology and the disease pathogenesis that is caused by $\mathrm{Cd}$.

Cd-induced autophagy has been reported in in vitro and in vivo models (19-21). A previous study has shown that Cd-induced autophagic death is dependent on ROS activation in skin epidermal cells (22). However, the function and mechanism of autophagy remains unknown. The results of the present study indicate that $\mathrm{Cd}$-induced ROS increase is closely associated with protective autophagy in PC-12 cells. Inhibition of autophagy, by the addition of CQ, resulted in a further decreased capacity to reduce mitochondrial content and an increased sensitivity to $\mathrm{Cd}$, which supports the hypothesis that autophagy is a cellular protective mechanism response to Cd treatment. Notably, NAC reduced intracellular ROS levels and decreased Cd-induced autophagy, but enhanced the mitochondrial damage and apoptotic cell death that was induced 
by the inhibition of autophagy. Previous studies demonstrated that high levels of intracellular glutathione inhibit mitophagy in yeast (23) and increased superoxide anion production stimulates mitophagy (24), which supports the findings of the present study that increased ROS, induced by $\mathrm{Cd}$, acts as a signaling molecule to activate mitophagy.

Generation of ROS is hypothesized to be the basis for Cd-induced toxicity. In certain instances, ROS formation induced by $\mathrm{Cd}$ depletes endogenous redox scavengers, inhibits antioxidant enzymes and the mitochondrial electron transport chain, causes mitochondrial damage, and triggers apoptosis and necrosis $(8,25,26)$. However, Cd-induced ROS formation also activates various antioxidative components as a result of a disturbed redox balance and a consecutively induced signal transduction cascade (18). The result of the present study indicated that an appropriate quantity of ROS is not harmful, but essential in order to induce autophagy for cell survival. The initial ROS response to $\mathrm{Cd}$ induction is an initiation of autophagy to enable self-clearance. Autophagy may act as a cellular antioxidation defense mechanism, although its function is not inherently antioxidative. Notably, in the present study when autophagy was inhibited and the PC-12 cells were exposed to $\mathrm{Cd}$ at a late stage $(24 \mathrm{~h})$, ROS accumulation was observed in the PC-12 cells; however, apoptosis and necrosis also became evident at this point. These results indicate that a massive and persistent ROS is likely to be accompanied by an induction of mitochondrial dysfunction leading to cell death, which is consistent with the hypothesis of neuronal cell death as a consequence of increased oxidative stress (11). The underlying reason for these variances remains unknown, however might be associated with differences in the capacity to activate autophagy, the quantity of ROS and the time exposed to $\mathrm{Cd}$. Therefore, oxidative stress is hypothesized to be essential for cell survival to trigger autophagy at the initial stage. As an increasing quantity of $\mathrm{Cd}$ enters into cells, the overwhelming oxidative stress may be harmful to those cells. Further studies are required to investigate the ROS threshold in cell survival and death.

The crosstalk between autophagy, redox signaling and mitochondrial dysfunction is not well understood (10). Mitochondria are generators of and targets for ROS, and oxidative stress is indivisibly linked to mitochondrial dysfunction (27). Mitochondrial turnover is dependent on autophagy, which results in membrane potential variances, ROS production (28) and occasionally cell death (29). Under certain stress conditions, one possible explanation is that the accumulation of toxic proteins and the decrease in mitochondrial function leads to further overwhelming oxidative stress when the autophagic process is disrupted (30-32). By contrast, redox signaling or mitochondrial dysfunction may also influence autophagy. The results of the present study conform to these two hypotheses. Although ROS production has been identified as demonstrating a positive role in $\mathrm{Cd}$-induced autophagy, it remains unclear as to which species of ROS activate the autophagy in Cd-treated PC-12 cells. Furthermore, the present findings do not exclude the possibility that mitochondrial dysfunction is also involved in the induction of autophagy, as ROS production may result from either the mitochondria themselves or the plasma membrane oxidases (33). Further investigation is required to resolve these queries.
In conclusion, autophagy has been demonstrated as significant in PC-12 cell survival following Cd treatment. At the early stages of Cd exposure, ROS function as signaling molecules to trigger autophagy as a survival mechanism in $\mathrm{Cd}$-induced oxidative stress. However, excessive ROS production may lead to cell death (Fig. 4). The present study provides an insight for future investigation of $\mathrm{Cd}$-induced neurotoxicity.

\section{Acknowledgements}

The present study was supported by the National Natural Science Foundation of China (grant nos. 31302058, 31101866 and 31172373), a Project Funded by the Priority Academic Program Development of Jiangsu Higher Education Institutions (PAPD) and the Joint Foundation of Guizhou Province (grant no. LKB [2013]02). The authors would like to thank Dr Maozhi $\mathrm{Hu}$ for technical assistance in flow cytometry analysis.

\section{References}

1. Templeton DM and Liu Y: Multiple roles of cadmium in cell death and survival. Chem Biol Interact 188: 267-275, 2010.

2. Lukawski K, Nieradko B and Sieklucka-Dziuba M: Effects of cadmium on memory processes in mice exposed to transient cerebral oligemia. Neurotoxicol Teratol 27: 575-584, 2005.

3. Curtis JT, Hood AN, Chen Y, Cobb GP and Wallace DR: Chronic metals ingestion by prairie voles produces sex-specific deficits in social behavior: an animal model of autism. Behav Brain Res 213: 42-49, 2010.

4. Mascagni P, Consonni D, Bregante G, Chiappino G and Toffoletto F: Olfactory function in workers exposed to moderate airborne cadmium levels. Neurotoxicology 24: 717-724, 2003.

5. Fernández-Pérez B, Caride A, Cabaleiro T and Lafuente A: Cadmium effects on $24 \mathrm{~h}$ changes in glutamate, aspartate, glutamine, GABA and taurine content of rat striatum. J Trace Elem Med Biol 24: 212-218, 2010.

6. Minami A, Takeda A, Nishibaba D, Takefuta S and Oku N: Cadmium toxicity in synaptic neurotransmission in the brain. Brain Res 894: 336-339, 2001.

7. Schapira AH and Gegg M: Mitochondrial contribution to Parkinson's disease pathogenesis. Parkinsons Dis 2011: 159160, 2011.

8. Thévenod F: Cadmium and cellular signaling cascades: to be or not to be? Toxicol Appl Pharmacol 238: 221-239, 2009.

9. Bertin G and Averbeck D: Cadmium: cellular effects, modifications of biomolecules, modulation of DNA repair and genotoxic consequences (a review). Biochimie 88: 1549-1559, 2006.

10. Lee J, Giordano S and Zhang J: Autophagy, mitochondria and oxidative stress: cross-talk and redox signalling. Biochem J 441: 523-540, 2012.

11. Chen L, Xu B, Liu L, Luo Y, Zhou H, Chen W, Shen T, Han X, Kontos $\mathrm{CD}$ and Huang S: Cadmium induction of reactive oxygen species activates the mTOR pathway, leading to neuronal cell death. Free Radic Biol Med 50: 624-632, 2011.

12. Lavallard VJ, Meijer AJ, Codogno P and Gual P: Autophagy, signaling and obesity. Pharmacol Res 66: 513-525, 2012.

13. Klionsky DJ, Abdalla FC, Abeliovich H, Abraham RT, Acevedo-Arozena A, Adeli K, Agholme L, Agnello M, Agostinis P, Aguirre-Ghiso JA, et al: Guidelines for the use and interpretation of assays for monitoring autophagy. Autophagy 8: 445-544, 2012.

14. Scarlatti F, Granata R, Meijer AJ and Codogno P: Does autophagy have a license to kill mammalian cells? Cell Death Differ 16: 12-20, 2009.

15. Scherz-Shouval R and Elazar Z: ROS, mitochondria and the regulation of autophagy. Trends Cell Biol 17: 422-427, 2007.

16. Wang Q, Zhu J, Zhang K, Jiang C, Wang Y, Yuan Y, Bian J, Liu X, Gu J and Liu Z: Induction of cytoprotective autophagy in PC-12 cells by cadmium. Biochem Biophys Res Commun 438: 186-192, 2013.

17. Krysko DV, Vanden Berghe T, D'Herde K and Vandenabeele P: Apoptosis and necrosis: detection, discrimination and phagocytosis. Methods 44: 205-221, 2008. 
18. Cuypers A, Plusquin M, Remans T, Jozefczak M, Keunen E, Gielen H, Opdenakker K, Nair AR, Munters E, Artois TJ, et al: Cadmium stress: an oxidative challenge. Biometals 23: 927-940, 2010.

19. Thévenod F and Lee WK: Cadmium and cellular signaling cascades: interactions between cell death and survival pathways. Arch Toxicol 87: 1743-1786, 2013.

20. Chiarelli R, Agnello M, Bosco L and Roccheri MC: Sea urchin embryos exposed to cadmium as an experimental model for studying the relationship between autophagy and apoptosis. Mar Environ Res 93: 47-55, 2014

21. Chargui A, Zekri S, Jacquillet G, Rubera I, Ilie M, Belaid A Duranton C, Tauc M,Hofman P,PoujeolP, et al: Cadmium-induced autophagy in rat kidney: an early biomarker of subtoxic exposure. Toxicol Sci 121: 31-42, 2011

22. Son YO, Wang X, Hitron JA, Zhang Z, Cheng S, Budhraja A, Ding S, Lee JC and Shi X: Cadmium induces autophagy through ROS-dependent activation of the LKB1-AMPK signaling in skin epidermal cells. Toxicol Appl Pharmacol 255: 287-296, 2011.

23. Deffieu M, Bhatia-Kissová I, Salin B, Galinier A, Manon S and Camougrand N: Glutathione participates in the regulation of mitophagy in yeast. J Biol Chem 284: 14828-14837, 2009.

24. Kim EH and Choi KS: A critical role of superoxide anion in selenite-induced mitophagic cell death. Autophagy 4: 76-78, 2008

25. Thévenod F: Catch me if you can! Novel aspects of cadmium transport in mammalian cells. Biometals 23: 857-875, 2010.
26. López E, Arce C, Oset-Gasque MJ, Cañadas S and González MP: Cadmium induces reactive oxygen species generation and lipid peroxidation in cortical neurons in culture. Free Radic Biol Med 40: 940-951, 2006.

27. Murphy MP: How mitochondria produce reactive oxygen species. Biochem J 417: 1-13, 2009.

28. Yen WL and Klionsky DJ: How to live long and prosper: autophagy, mitochondria, and aging. Physiology (Bethesda) 23: 248-262, 2008

29. Luo YH, Wu SB, Wei YH, Chen YC, Tsai MH, Ho CC, Lin SY, Yang CS and Lin P: Cadmium-based quantum dot induced autophagy formation for cell survival via oxidative stress. Chem Res Toxicol 26: 662-673, 2013

30. Hashimoto M, Rockenstein E, Crews L and Masliah E: Role of protein aggregation in mitochondrial dysfunction and neurodegeneration in Alzheimer's and Parkinson's diseases. Neuromolecular Med 4: 21-36, 2003.

31. Gottlieb RA and Carreira RS: Autophagy in health and disease. 5. Mitophagy as a way of life. Am J Physiol Cell Physiol 299: C203-C210, 2010.

32. Schneider L and Zhang J: Lysosomal function in macromolecular homeostasis and bioenergetics in Parkinson's disease. Mol Neurodegener 5: 14, 2010.

33. Thannickal VJ and Fanburg BL: Reactive oxygen species in cell signaling. Am J Physiol Lung Cell Mol Physiol 279: L1005-L1028, 2000. 